\title{
Awareness of Critical Discourse Analysis Underpins Learners' Sociolinguistic Competence and Language Use
}

\author{
Fawzi Al Ghazali a * (D) \\ ${ }^{a}$ Al Hosn University, P.O. Box38772, Abu Dhabi, UAE
}

\begin{abstract}
As a special approach in discourse analysis, Critical Discourse Analysis (CDA) aims to study the discursive conditions and consequences of power abuse practised by dominant groups or institutions (van Dijk, 1995). It contributes to raising awareness of the discursive strategies employed by elite groups in order to control the minds of minor ones. It permits them to free themselves from the compulsions and limitations that deprive them of their right to think critically and have the freedom of choice. In the discipline of language learning, learners' awareness of CDA enables them to read critically and produce language in more logical manner. It is one way to empower them with adequate reading and writing strategies and to enhance their consciousness of using speech acts in meaningful context. This paper analyses a text following the framework of text analysis proposed by Fairclough (1992). The authentic text was selected reflecting one aspect of the British culture that does not have the common agreement of the ruling parties in the British community. It holds significant debate between representatives of the Conservative Party and the Labour Party that was taking over at that time. The analysis shows how the lexical and syntactic connotations reflect the attitudes of each Party and the newspaper publishing this article as well. The paper provides insights into how CDA can enhance learners' sociolinguistic competence and language use.
\end{abstract}

(C) 2017 EJAL \& the Authors. Published by Eurasian Journal of Applied Linguistics (EJAL). This is an open-access article distributed under the terms and conditions of the Creative Commons Attribution license (CC BY-NC-ND) (http://creativecommons.org/licenses/by-nc-nd/4.0/).

Keywords: Linguistic Competence; CDA; Language Use, Language Register; Sociolinguistics

\section{Introduction}

\subsection{Scope of the Topic}

Critical discourse analysis (CDA) construes normal discourse as a form of social practice in produced language that is socially influenced and influential. It aims to understand the relationship between language register, power, and ideology (Cots, 2006). It is a creative and disciplined enterprise based on a speech act theory that says that language is used not only to describe things but to do things as well (Brown and Yule, 1985). It focuses on language as it is used by real people with real intentions, emotions, and purposes. People are members of the society and their speech is a reflection of a set of experiential, relational, and expressive values

\footnotetext{
* Fawzi Al Ghazali.

E-mail address: f.alghazali@alhosnu.ae

http://dx.doi.org/......
} 
(Fairclough, 1992: 110). According to this approach, there is a correlation between linguistic production and social variables. For Fairclough, CDA is an orientation towards language which associates linguistic text analysis with a social theory of the functioning of language in political and ideological processes. Identifying these processes helps not only to identify the internal blocks of discourse described by Gee (2001: 92) but also to identify the connotations it implies. Integrating CDA in language courses permits learners to develop their capacities so as to examine and judge the world around them and possibly change it through intended discourse. Learners' awareness of CDA also allows them to use language in a pragmatic way for fulfilling different language purposes.

To signify the merits of CDA over normal discourse analysis, Van Dijk (1995: 17) outlines that CDA goes beyond the direct description of language used in texts. Rather, it is a problem - oriented approach that studies all forms of social inequality such as sexism, racism, or colonialism. It focuses on group relations of power, dominance, and inequality that are reproduced or resisted by social group members through text and talk. It therefore aims to uncover, reveal, or disclose what is implicit or what is not explicitly expressed in the discourse of the dominated group (ibid: 18). It permits oppressed or marginalized groups to formulate, develop, and enact counterpower and counter-ideologies in practices of challenge and resistance. Expressing the discursive conditions, components and consequences of power abuse of dominant elite groups or institutions is not the mere aim of CDA. Another perspective is the revealing of bias and prejudice in the discourse of certain groups over other groups affected by some ideologies that drive them to take up an attitude for or against an institution like the government, for instance.

Like van Dijk, Wodak (2007) clarifies that the term 'Critical' means not taking things for granted by being more reflective and sometimes 'skeptical' on verbal and written discourse. This particularly happens in situations when the writer or interlocutor maintains less neutral or more prejudiced views on some issues. The critically analyzed text in this paper reflects the viewpoint of the British Conservative Party (CP) against the measures taken by the Labour Party (LP) on drug use, dealing, and trafficking. The text carries claims and counter-claims from both parties and shows the ideology underlying the production of claims in comparison to the counterclaims of the other party.

\subsection{Significance of the Topic}

This study investigates the fact that the composition of spoken and written discourse is driven by certain philosophies, ideologies, and doctrines. Knowledge of CDA allows for understanding the sociolinguistic implications of discourse and for enhancing language use accordingly. From a sociolinguistic perspective, it raises the awareness of language users of the many discursive strategies employed by writers to impose a certain idea or to get audience satisfied with a certain doctrine or ideology. The selection of lexical expressions along with the way phrases and sentences are 
structured all consolidate the viewpoint of the writer. From a pedagogic perspective, learners' awareness of CDA enables them to read critically and produce language in more logical manner. It empowers them with adequate reading and writing strategies and to enhance their consciousness of using speech acts in meaningful context.

\section{Literature Review}

\subsection{Definition of CDA}

According to Tenorio (2011), CDA is naturally embedded within critical theory that was originated to critique and change society and help actors to emancipate themselves from domination and authority of other dominated groups. It reveals structures of power and ideologies behind discourse by making visible causes that are hidden. It sometimes questions the status quo by resisting power abuse as transmitted in private and public discourses. He (2003: 428), in addition, argues that the word 'discourse' involves a big ' $\mathrm{D}$ ' and a small ' $d$ '. The big ' $\mathrm{D}$ ' relates to the general ways of viewing the world and general ways of behaving (including speaking); whereas the small ' $d$ ' concerns actual language use. CDA accordingly is used to clarify how sociocultural knowledge is related to the performance and use of speech acts. It is given without saying that various approaches have been developed for applying CDA. They aim to investigate the production, interpretation, and explanation of everyday action through conversation. Unlike CDA, discourse analysis is non-critical, for it is concerned with the description of discursive practices and forms of oral and written interaction (2003). Halliday (1978), taking his inspiration from the work of Firth, adopts another approach in which he proposes that language is a social semiotic and that linguistic form is affected systematically by social circumstances. He points out that every cultural group has its home-based discourse which marks its identity. Hence, people may have different identities due to their different discursive practices.

Gee (1990: 81) and Sampson (1980: 62) argue that CDA is the process in which various discourse types are encoded and interpreted particularly in the context of their formations and social semiotics. Van Dijk (1996: 86) claims that discourse types are influenced by social power exercised by a dominant group over the actions and minds of another group. Such power limits their freedom and influences their knowledge, attitudes, ideologies and speech. Fowler (1996:4) argues that the goals of discourse analysts should be defamiliarisation and consciousness-raising. They should provide a 'critique' rather than a 'criticism' in order to help the reader understand the social background and motives influencing the composition of discourse. For example, Coulthard (2001: 5) argues that femininity is misrepresented in sex narratives which hinge on paradoxes and social asymmetries, such as a women's magazine.

Fairclough (1992) asserts the relationship between language and power. He claims that discourse is a social practice. His framework is critical in that it depends not only on the description of discursive practices but also on the interpretation and explanation of how discourse is shaped by relations of power and ideologies. According 
to this view, critical discourse analysis demonstrates the constructive effects discourse has upon social identities, social relations and systems of knowledge and belief, none of which is normally apparent to discourse participants.

\subsection{Discourse Analysis and Language Teaching}

Before considering discourse analysis as a core branch of linguistics, language teaching has been concerned with grammatical rather than communicative competence. The situations created for language delivery are more pedagogic, adapted, and less authentic bearing little resemblance of natural, automatic language use. Following on from the work of Canale (1982), communicative competence has been largely regarded as a quadrilateral figure composed of four areas of knowledge and skill. The first of them is grammatical competence which is concerned with the learner's ability to express the literal meaning of utterances. The second is the sociolinguistic competence which is concerned with the ability of the learner to select the appropriate form and appropriate meaning to convey a message or express an idea using the most appropriate speech acts. The third component is the discourse competence which keeps the coherence and cohesion in the structure of a text and allows the learner to identify the appropriate organization of ideas in a text. Lastly, it is the strategic competence which is concerned with the employment of verbal and non-verbal strategies when expressing an idea.

It is then evident that knowledge of discourse analysis goes beyond the skill of guessing the implicit ideas or identifying the tone, attitude, and bias of a writer. It has more constructive function in permitting the leaner to identify the optimal organization of ideas in a speech or a report. A leaner can resort to the claimcounterclaim textual organization when reflecting on two different viewpoints of the same topic. The problem-solution textual organization can be also applied in case the topic has a cause-effect nature. Learning a foreign language moves from just being a medium of reporting and describing things to a medium of classifying the functions utterances can perform in different situations with different audience. In classical classroom language instruction, language use normally takes the form of citation (repeating or combining sentences), simulation (role playing), or replication (creating similar situations to use certain speech acts, for instance).

Furthermore, raising learners' consciousness and awareness of discourse analysis allows them to use anaphoric and cataphoric references more effectively and reduces unnecessary repetition and redundancies in a text. It also enables them to use substitution is situation when there is no need to literally repeat the same nominal, verbal or clausal items. Ellipsis is another skill foreign language learners can acquire through knowledge of discourse analysis. In spoken and written forms, some utterances can be deleted in situations when they are easily guessed or figured out through the overall context. The use of cohesive devices like coordinating conjunctions or (FAN BOYS), conjunctive adverbs (however, therefore, nevertheless, etc.), and subordinators (while, although, because, etc.) is also indicative of appropriate 
communicative competence. Lastly, lexical ties are other devices used to eliminate monotony in spoken and written discourse. Having a good wealth of vocabulary is not enough unless the speaker or writer knows how to manipulate them in discourse. Using synonyms, near synonyms, antonyms, or metonymy are different forms of lexical devices. Knowledge of how a text is composed, how ideas are organized, and which lexical items are appropriate indirectly underpins learners' skill of using language in more pragmatic manner. Using Fairclough's framework for CDA, I provided a practical critical discourse analysis of a text to show how the choice of lexical items and grammar formations is influential.

\subsection{Framework for $C D A$}

According to Fairclough (1992: 110-12), the critical discourse analysis of a text should pass through the three stages of description, interpretation of the relationship between text and interaction, and explanation of the relationship between interaction and social context. In this approach, he distinguishes between three types of value that formal features of a text may have. The first is the experiential value in which the text producer's experience of the natural and social world is represented through the content in the form of personal knowledge and beliefs. The second is the relational value in which the social relationships are enacted via the text in the discourse, and the third is the expressive value in which the producer of a text evaluates an aspect of reality or social identities. Fairclough points out that the choice of vocabulary, grammar and textual structures to make up the formal features of a text is determined by these values. Though Fairclough is not the only writer to assert the social nature of language, his key insights are that discourse is shaped primarily by power relations in society, and that discourse shapes social relations, as well as being shaped by them. He argues that language serves to construct particular political positions which entail unequal relations of power.

Hence, the CDA framework applied in this paper goes beyond investigating the lexical and grammatical relations of a text. Rather, it acts as a possible agent of understanding the attitudinal and social interactions underlying the composition of a certain discourse and as a means of social change, especially in its use in the classroom. Gee, (2001: 92-94) and Halliday (1978), on the other hand, have dissimilar approaches to CDA in that they give equal focus to the internal building of a text where lexical and grammatical cohesion is also scrutinized.

\section{Text Analysis}

The text (appendix 1) is a news story from (The Daily Telegraph) newspaper and is 434 words long. It demonstrates the current statistics of drug use, particularly cocaine, among the urban middle classes. The figures show that cocaine use has shot up within the past ten years. The text lays much blame on the government on the grounds that the rigidity it maintains in reclassifying drugs participates in increasing 
the number of illegal drug users and traffickers. This text, however, involves different points of view which are discussed in the sections below.

\subsection{Text Headline and Underlying Ideology}

The text headline (Home Office resists reform of drug law as cocaine use doubles) implies a critical point of view. No wonder that the Daily Telegraph draws an unpleasant picture of the precautionary measures taken by Labour government in its war on drugs since the newspaper represents the right-wing (Conservative) viewpoint which expectedly challenges the Labour government. The headline reflects the ideological background of the writer and the newspaper as well. It appears as an 'active' sentence to give prominence to the Home Office as the agent resisting reform and the main factor behind the multiplication of cocaine use accordingly. Passivizing the headline (Reform of drug law is resisted by the Home Office) could hardly convey the same message. The use of 'doubles' indicates the failure of the government in dealing with the problem. If the same story were published in 'The Guardian' or 'The Independent' newspapers, for example, the headline might be less prejudiced such as (Home Office considers reform of drug law) showing that the government is willing to reconsider the current drug system. This headline is a clear example of the relation between language and power claimed by Fairclough (1992) since it reflects the relational and attitudinal values of text producer.

\subsection{Analyzing Contexts}

In investigating the context of culture, the text reflects a side of British culture which views the use of drugs, particularly alcoholic drinks, as part of people's social life. It tries to increase pressure on the government for the reclassification of drugs, as suggested in 1971, in terms of what should be assigned for personal use and what should attract higher penalties. According to the text, the current classification system is viewed by concerned organizations in the UK as out-of-date, both in terms of new patterns of drug use and new information about their effects. The government alleges that the present system of classifying drugs has proved effective, and is unwilling to review the drug classification system as a whole; however, it has agreed to make some specific changes - such as adding crystal meth to the class A (most dangerous) list. It seems that the government is willing to make changes that move towards more strictness but not changes that would lead to more leniency.

The writer has enriched the text with claims and counterclaims that help create a context of situation implying that drugs are the most dangerous threat to community cohesion and that the Labour government is always wrong. The statements made by representatives both of the government (Vernon Coaker) and of a drugs-related charitable organization (Martin Barnes) reflect a certain ideological and attitudinal background. Coaker views that the current system works effectively and the government has achieved remarkable progress in its war on drugs; whereas Barnes' point of view is that the government's unjustified inflexibility to reform the drug 
classification system doubled the number of drug users in the past eight years. The writer's social power is expressed through the careful selection of vocabulary and statement formation whereas enhancing the text with many claims in comparison with the few counterclaims provided only by Coaker reflects a certain satisfaction. Examples of this are analyzed in the following sections.

\subsection{Ideational Meaning and Transitivity: Process Types}

A particularly marked transitivity feature of the text is the high proportion of show/report relational processes. Since the text is mainly argumentative involving claims and counterclaims, enhanced by the statistics revealed by the British Crime Survey, it is full of reporting relational processes which make up about $50 \%$ of all verb groups like show, indicate, reporting, estimated, confirmed, etc. Below are some examples from the text:

The latest official figures show ...

The British Crime Survey indicates ...

The government ... claimed yesterday that ...

The awesome use of 'copula' verbs is another example of relational processes found in the text.

Cocaine use is on the rise among ...

Drug treatment providers ... are under financial pressure ...

I believe that the existing classification system does this effectively ...

Mental processes are signaled in the text in very few examples like:

Overall drug use ... appears to have declined ...

The door seems to have been left open to ...

I believe the existing classification system ...

The text, however, incorporates no examples of physical or material processes because the issue is of an abstract and expositional nature more than a concrete one.

\subsection{Ideational Meaning and Transitivity: Participants and Nominalization}

The writer manages to assure his absence in the text. His retreat into individual invisibility is probably in order to make his authority more impersonal, and thus more difficult to question. His views are implicitly expressed, but his political orientation could be noticed in sentence 7 where he gives a negative evaluation of the government policy. In sentence 8 , the use of decided and or shows that the government is too rigid to accept making necessary reformations and that its decision is non-negotiable regardless of the bad consequences this strictness may create. The counterviews 
conversely show that the government is really working, yet according to a different plan.

(7) But figures also show little progress on Class A substances, such as cocaine.

(8) The Home Office has decided not to reform the drugs classification system or to introduce new thresholds for possession of illicit substances.

The writer's exposition is foregrounded by human participants like Vernon Coaker and Martin Barnes, in addition to the survey carried out by the BBC to give credibility to the source. The text also involves non-human active participants such as cocaine use, drug classification system, and illicit substances. The nominalization of cocaine as getting the highest percentage putting it at the top of other drugs indicates how this substance has become popular; whereas the nominalization of cannabis and Methylamphetamine or Crystal meth raises the alarm about the bad effects of these substances on community cohesion. Moreover, there are two other prominent nominalizations in sentences 1 and 3 :

(1) Cocaine use is on the rise among the urban middle classes

(3) ...cocaine has shot up since Labour took office ...

The nominalization of the urban middle classes as cocaine users could have some implications as:

a. cocaine is popular among urban classes and probably not the rural ones;

b. cocaine is popular among urban classes because they can afford it;

c. the rural classes, if they are drug users, use other inferior substances;

d. the poorer classes, whether urban or rural, do not use cocaine because it is costly.

The nominalization of the Labour Party could also have more implications as:

a. the government failed to reduce the percentage of drug use within the past eight years;

b. drugs reclassification is a necessity because the current system is not working;

c. the government is always inflexible in the face of any threat or alleged danger.

\subsection{Interpersonal Meaning and Modality}

The interpersonal meaning of language maintains social relationships between people and includes forms of address, speech function and modality. It is one of the three functions Halliday (1978:35) considers as available in any language namely 'the ideational function' and 'the textual function'. Modality, on the other hand, includes any unit of language that expresses the speaker/writer's affinity with propositional and evaluative structures. It has different types and degrees because modal verbs imply different degrees of affinity. The clearness of the issue gives predominance of unmodalized polar statements and forces the writer to obviate the extensive use of 
other markers of modality. In the text, there are few examples that can be said to reflect the writer's own attitude. His use of illicit indicates that he views all illegal drugs with an equal degree of disapproval, regardless of the amount of damage they may or may not cause. In addition, describing the 500 joints considered for personal use as being the most liberal is given as an example of a liberal proposal that would horrify the average Telegraph reader. Other modality types are found relating to Coaker and Barnes reflecting their appreciation of the problem.

(11) There is a coherent system in place to categorize ... (Coaker)

(13) We are extremely disappointed that the government has reversed... (Barnes)

The above sentences reflect Coaker's contention that the current drug system is effective and strict penalties are determined for drugs' manufactures, possession and supply; whereas Barnes' argument is that the increase in drug use and in drugrelated problems within the past few years is due to the ineffective current system which was produced 35 years ago, and this explains his disappointment. This text is rich in attitudinal epithets and adverbs that are considered necessary for the enhancement of either point of view such as:

(12) I believe that the existing classification system does this effectively. (14) ... we have significant increase in levels of drug use and drug-related harms.

\subsection{Interdiscursivity}

The writer draws upon a variety of discourse types in the composition of the text. Though the whole text is designed in a form that maintains a semi-formal style which is expected in this genre, he switches freely between informal spoken style and language that might be considered academic. The use of spliffs, for example, in sentence (9) to refer to young drug users is informal the same like the use of crystal meth in sentence (15) instead of methylamphetamine which is academic. The writer's neutral language keeps him out of interrogation and also offers a release from expectations of rigour and precision that a more formal style may evoke in the readership, thus giving the topic more popularity.

\subsection{Reiteration}

According to Winter (2001: 46), reiteration is the repetition of certain lexical items used either for the confirmation of the discussed idea or because they relate to the same lexical set of the discussed topic. It can be carried out explicitly using the identical item in many sentences or implicitly using synonymy, near-synonymy or antonym of the original items. Fairclough lays much interest on the ideologically significant meaning relations in a text. In this text, there are several examples of reiteration. The writer resorts to 'over-wording' to give prominence to the issue and to 
indicate that it is a focus of ideological struggle; whereas synonyms and antonyms are other means of implicit 'rewording'. This clearly appears in the table below.

Table 1: Implicit reiteration in the text

\begin{tabular}{||l|l|l|l|l|l||}
\hline \hline No & Reiteration & Type & No & Reiteration & Type \\
\hline 1 & show, indicate & synonymy & 8 & illegal, illicit & synonymy \\
\hline 2 & appear, seem & synonymy & 9 & strategy, plan & synonymy \\
\hline 3 & rise, increase & synonymy & 10 & categorize, classify & synonymy \\
\hline 4 & figures, numbers & synonymy & 11 & rejected, reversed & near- synonymy \\
\hline 5 & previous, earlier & synonymy & 12 & doubled, shot up & near-synonymy \\
\hline 6 & supply, provide & synonymy & 13 & report, claim, said & near- synonymy \\
\hline 7 & existing, current & synonymy & 14 & shot up \# declined & antonym \\
\hline \hline
\end{tabular}

The text has three examples of explicit reiteration where some items are used as verbs and in other sentences as nouns, but it has no examples of echoic emphatic items.

\begin{tabular}{|ll|}
\hline (1) The latest official figures show & (7) Figures also show little progress on Class A \\
(9) A significant tightening where & (14) We have seen a significant increase in \\
(13) ... review the system of drug & (17) Others are under review (N) and beds are ... \\
\hline
\end{tabular}

\subsection{Other Constructive Features in the Text}

Fairclough (1992: 120) concentrates on the relation between the choice of language and the social power underlying it. In the text, the writer's choice of words and tenses reflects a certain ideology and a social background. Here are other relevant points:

Most of the sentences are active and the agents are clear. The nominalization of cocaine use, use of cocaine, overall drug use sets these up as processes with no clear human agent - though linked by implication with Government mismanagement by tying the figures to the period since Labour took office. The absence of non-human agents probably arises from the writer's contention that not only is the government the responsible agent behind the complication of the drug problem, but that people are also true participants in creating it.

The text contains both positive and negative sentences. The positive sentences refer to the latest figures besides the government's advocacy of the current system; whereas the negative ones display the counterviews. Negation in the text is expressed explicitly through the negative article 'not', and implicitly through items that imply negative meaning such as disappointed, rejected, reversed, and refused. In addition, words of contrast (but, however, etc.) are the most common clause relations to cope with the claims and counterclaims.

The writer used two main tenses in composing the text that may help convey his message. He used the 'present simple' to express a permanent fact - the increasing number of drug users - and the 'present perfect' to indicate recent events which could 
have some effect on the situation as a whole, e.g. the government's refusal to undertake an overall reclassification exercise.

The issue of drug use is an area of ideological contest (Fairclough, 1992: 117) especially when it is linked to young people indicating the possible corruption of the young, and a future vision of British society as one in which drug use would be acceptable.

Excessive evaluative words are used only in Barnes' counterclaims, and are attributed to him, not to the writer. In the text, no titles or addresses are used before Vernon Coaker or Martin Barnes. I think this is just in keeping with current usage in British journalism.

The text is not a florid piece of writing because the seriousness of the topic does not give much space for obvious rhetorical and metaphorical strategies but the overwhelming use of figures gives the writer's argument clarity and credibility.

Finally, the main information is placed at the beginning of the text. The first three sentences show the horrifying figures of cocaine use among the urban middle classes with reference to the British Crime Survey to enhance these figures and to give authority and prominence to the issue. The writer attributes this catastrophe to the Labour government in sentence (3).

\section{Patterning in the Text}

According to Francis (2001: 83) and Hoey (2001: 26), textual patterning is the ability gained by the writer to organize the text into meaningful paragraphs and cohesive clauses. Structuring a text using one pattern; however, does not preclude other forms of patterning. It is perfectly possible to find a general-specific structure embedded in a problem-solution pattern, or following on from it in the same text. This text represents an example of a multiple-pattern text. It is organized according to the claim-counterclaim textual patterning which is very common in political journalism and in letters-to-the-editor pages, and the stock-in-trade of many 'Compare and Contrast' academic essays. It can also be noticed as signaling a problem-solution pattern because the issue is so controversial. In the next section, I try to schematize these two patterns in the text to show how the textual structure asserted by Fairclough reflects the writer's ideational background.

\subsection{The Claim - Counterclaim Pattern}

According to McCarthy (1991: 81), the claim-counterclaim pattern is used to show two contrasting points of view. Uncovering the figures and statistics that show the rise in drug use in the UK within the past eight years with implicit reference to Labour government has paved the way for a set of claims and counterclaims. Moreover, the huge number of claims signaled by the writer in comparison with the counterclaims expressed by the current government members not only reflect his ideational background but also aims to satisfy 'The Daily Telegraph' readership. 
Below is a diagrammatic representation of the text from a claim-counterclaim point of view.

Common Ground: Sentences 1 and 2 show that cocaine use has doubled since 1998. This common ground is lexicallysignalled in: latest official figures, trends, surrey.

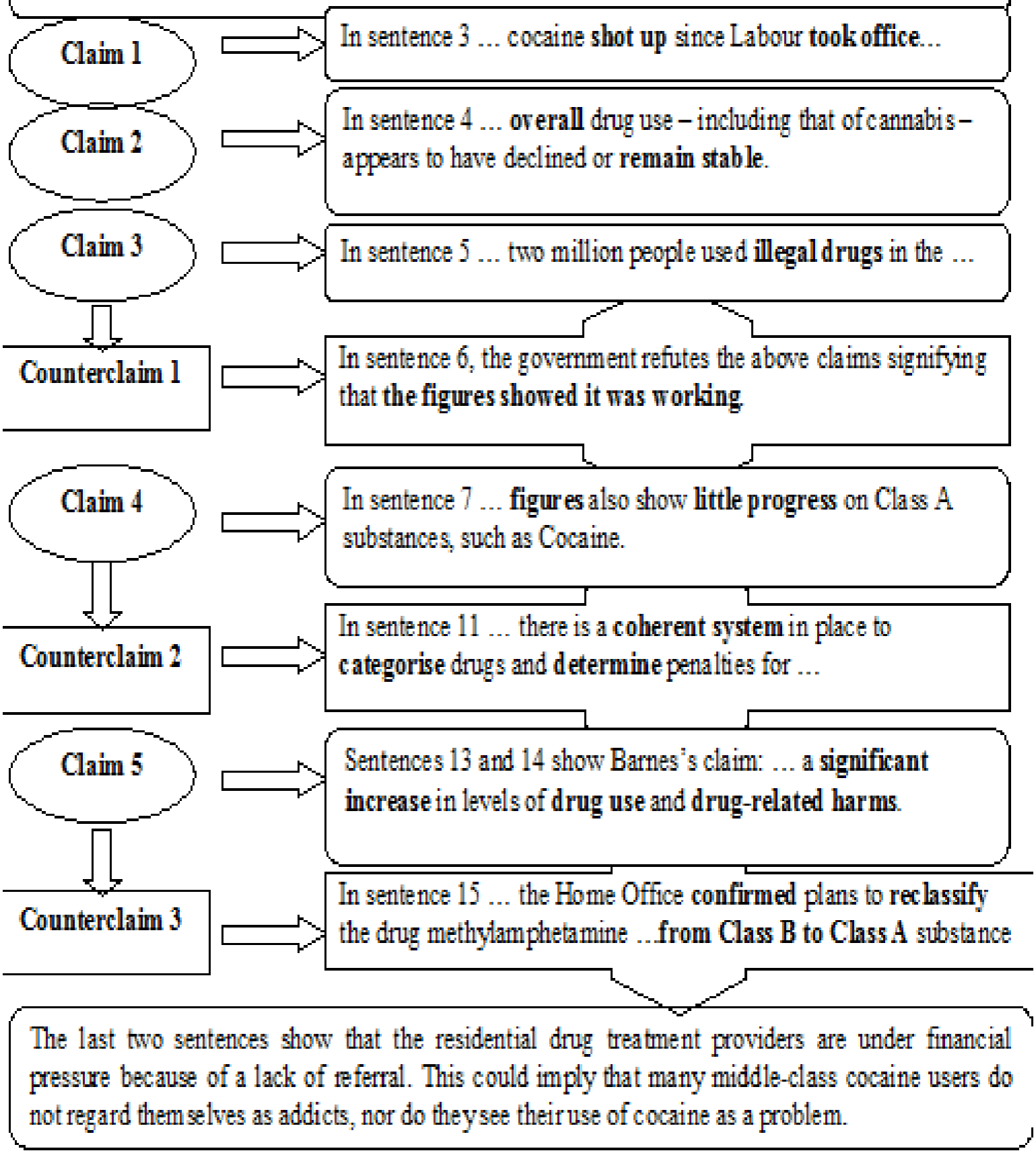

Figure 1: The claim-counterclaim textual patterning of the text 


\subsection{The Problem - Solution Pattern}

According to Hoey (1996: 150), the problem-solution structure consists of four categories: situation, problem, solution, and evaluation. The increasing number of drug users is a serious problem which gives space for these four categories to be found in clear text organization.

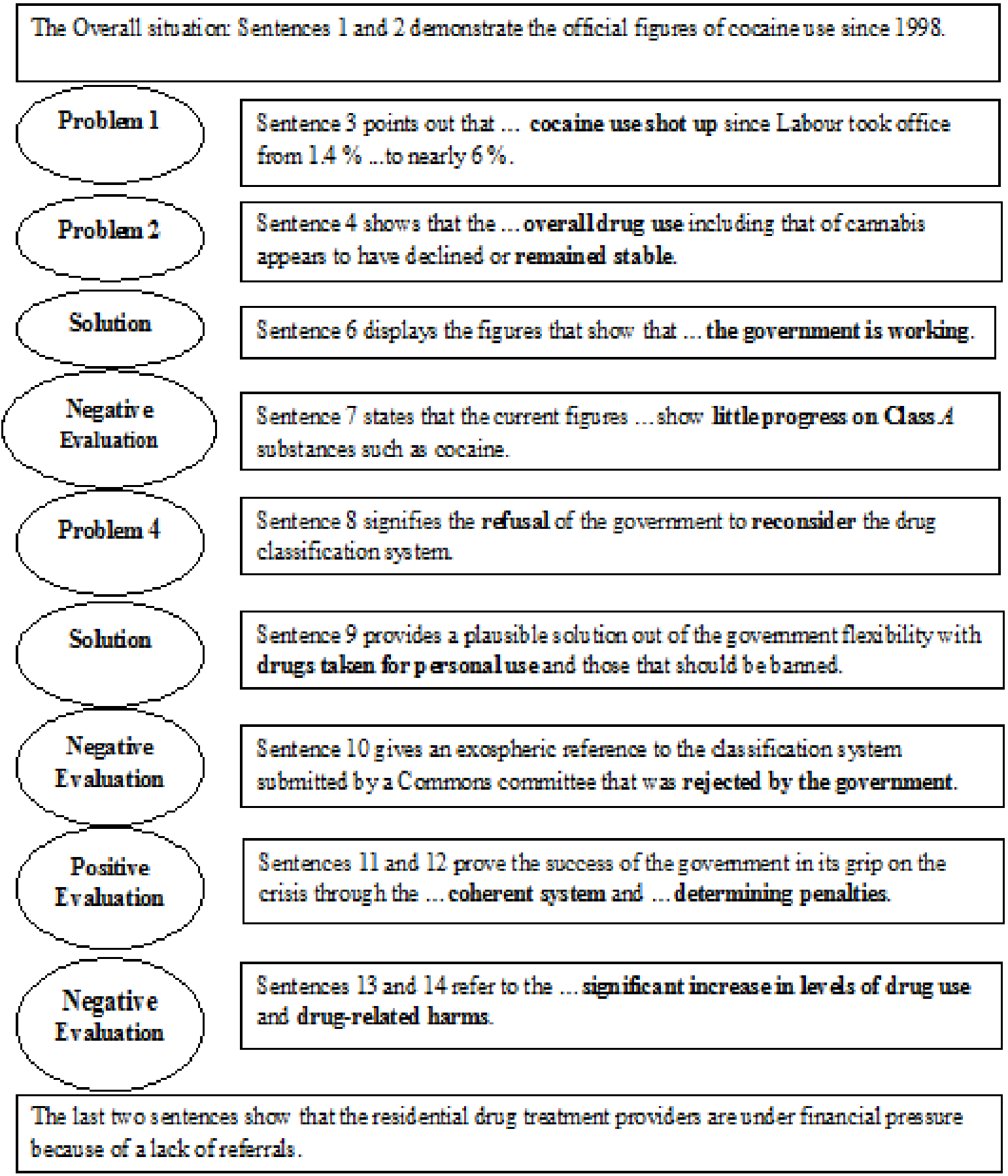

Figure 2: The problem-solution textual patterning of the text 


\section{The Implications of CDA in ELT Classrooms}

Analysis of the above text is indicative that language use has a functional aspect, and knowledge of it facilitates and enhances spontaneous, fluent communication. Knowing a list of glossaries is not enough unless accompanied by skill of how to use the appropriate vocabulary in certain situations. Awareness of using the same language expression in different discourses with different connotations and meanings is a merit maintained by skilled and competent learners. Erton (2000, p. 206) lists a number of examples of the functional analysis of conversation. He shows how the tag question, for instance, can be used to reflect different meanings. In the mini-dialogue "Gary: It's cold, isn't it?" and "Brian: Yes, it is not very warm", the tag "isn't it" is not really a request for confirmation but an invitation to the hearer to continue the conversation. In the second mini-dialogue, "Sue: He is Tom, is he?" and "Ellen: Yes, he is", the tag "is he" not only asks the hearer to agree that the statement is true, but also suggests that the speaker has just learnt, realized or remembered the information. In the third mini-dialogue "Colonel: Sit down, will you?" and "Lieutenant Gary: No, I won't.", the tag "will you" is not an expectation from the Colonel that Lieutenant Gary confirms or denies the information; it is rather an order, and that something bad may happen if Lieutenant Gary rejected it.

The tenet hereby is not rejection of teaching grammar, yet how grammar can be taught functionally by allowing learners to understand that a certain form can be used in different situations in different meanings. The deductive approach to teaching grammar does not offer opportunities for using the language forms functionally. Instead, teaching grammar forms inductively allows learners to see the situations in which these forms carry their different meanings. Whether through citation, simulation, or replication (Canale, 1983), those learners can understand the discourse in which these expressions are used with this exact meaning. The extensive studies in discourse analysis (text, context, conversation analysis, function) and pragmatics (speech acts, psychopragmatics, sociopragmatics, and pragmalinguistics) paved the way for such a change in the approach of teaching a foreign language. This movement encouraged approaches that combine teaching forms with functions to provide accuracy and fluency in the target language. Knowledge of vocabulary and grammar and being able to speak, read, and write sentences is not evidence of communicative competence unless accompanied with knowledge of why to use a certain expression and why to use it in this particular way. Analysis of discourse then can be a tool through which language teachers help learners to understand the different functions of language.

It is only through discourse analysis that learners can understand why they should say "fast car" but not "quick car", "fast food" but not "quick food", "quick glance" but not "fast glance", "quick meal" but not "fast meal" although "meal" and "food" have the same connotation, and "blonde hair" but not "blonde car" even if the car has the same blonde color. It is also through discourse analysis that language learners can understand the different textual organizations and the appropriate templates for each 
type of writing. The organization of a cause-effect essay surly differs from that of argumentative or persuasive essays. In addition, even within the cause-effect essay, there could be different internal textual patterning. In the chain organization pattern, language learners mention of each cause and its effect before moving to another cause and its effect. However, in the block organization, they write all the causes in one or two block paragraphs followed by the effects mostly in situations when the causes and effects are not directly related.

Critical discourse analysis, on the other hand, is an advanced step that necessitates higher levels of linguistic competence. Teaching it goes beyond raising learners' awareness of purely linguistic issues. It necessitates highlighting the effect of social power(s) on text composition accordingly. According to Richards, Platt, and Platt (1993: 343), CDA helps learners develop an ability to interpret speech acts that goes beyond understanding the propositional meaning of utterances to the illocutionary meaning, through the effect a written text may have on them as listeners or readers. Acquiring the skill of CDA enables learners to answer inferential questions whose answers are guessed because they often correlate with the writer's beliefs and ideologies. Gaining awareness of CDA, moreover, helps learners build a shield against extreme ideological opinions imposed - intentionally or incidentally - by teachers or other friends.

A language teacher can take some of these insights for the consciousness-raising of learners of the relation between language and power along with more general methods of discourse analysis to achieve a modified approach to CDA for use in ELT. This gives them strategic guidance for the improvement of discourse production through identification of discourse patterns, clause relations and genres (DudleyEvans, 2001: 220). The acquisition of such a skill promotes the logical organization of ideas and reinforces communication. However, the level of analysis depends on the linguistic level of learners. Wallace (1992: 61), for example, points out that CDA can be used to develop a reading methodology which addresses ideological assumptions as well as developing general reading comprehension. This definitely includes (i) the encouragement of reflective critical reading; and (ii) the extension of a 'pre-reading' / 'while-reading' / 'post-reading' procedures. This approach encourages learners to move away from focusing on form for its own sake to reinforcing the sociolinguistic competence and the use of language to explore and provide evidence of the text's ideological positioning.

\section{Conclusion}

The introduction of discourse analysis in language teaching is not optional should we need foreign language learners to use naturally-occurring language forms and lexical items functionally in an appropriate way that goes above the sentence level. Teachers, in addition, should encourage learners to study the discourse of language in a way that form and function should not be separated since they represent the two dimensions of the language. In many cases, there could be differences between 
functional interpretations of the same form in English. The communicative competence then goes beyond the normal verbal and written production of English; rather it covers the sensibility in using language forms and items in expressing a certain idea in the most effective way. While the appropriate selection of grammar forms and lexical items represents the elementary knowledge of language use, knowledge of word combinations or collocation is another merit of fluent, competent users of language.

An additional benefit of increasing learners' knowledge of CDA is that it allows them to understand that the production of discourse is not isolated from the existing social power, but affects and is affected by it. Competence in CDA deepens their understanding of the topics they read and promotes an ability to investigate the maneuvering some writers tend to employ in composing texts. This ability adds to understanding the mentality of writers whether they are capitalists, socialists, or religiously-committed persons (Gee, 2001).

My choice of the text from 'The Daily Telegraph' is not random. The Telegraph, which is a right-wing paper, tends to support the Conservative Party in most political views and is expected to oppose and challenge the Labour government. The writer, making use of the authority of the newspaper, managed to promote the view that drug use is bad and the government is to blame regardless of the efforts exerted to overcome the crisis. I think if the Conservative party were in power, the policy on drugs might be similar to that of the current Labour administration. The text clearly reflects the writer's commitment to the attitude of the newspaper. His exaggeration is expected to match the psychology of the newspaper's readership as well as the Conservative views.

\section{References}

Brown, G. \& Yule, G. (1985). Discourse Analysis. Cambridge: CUP.

Canale, M. (1983). "From Communicative Competence to Communicative Language Pedagogy" In J. Richards, J. and R. Schmidt (eds.) Language and Communication, London: Longman, p.2-27.

Cots, J. (2006). Teaching with an Attitude: Critical Discourse Analysis in EFL Teaching. ELT Journal, 60(4), 336-345.

Coulthard, R. M. (2001). On analyzing and evaluating written text. In Coulthard, R. M. (ed.) Advances in Written Text Analysis. London: Routledge.

Dudley-Evans, T. (2001). Genre analysis: An approach to text analysis for ESP. In Coulthard, R. M. (ed.) Advances in Written Text Analysis. London: Routledge.

Erton, I. (2000). Contribution of discourse analysis to language teaching. Hacettepe University Education Faculty Magazine, 19, 201-211.

Fairclough, N. (1992). Discourse and Social Change. London: Polity Press.

Fowler, R. (1996). On Critical Linguistics 1. In Caldas-Coulthard, C. R. and Coulthard, M. (eds.) Texts and Practices: Readings in Critical Discourse Analysis, London: Routledge.

Francis, G. (2001). Labelling discourse: an aspect of nominal-group lexical cohesion. In Coulthard, R. M. (ed.) Advances in Written Text Analysis. London: Routledge. 
Gee, J. P. (1990). Social Linguistics and Literacies: Ideology in Discourses. London: The Falmer Press.

Gee, J. P. (2001). An Introduction to discourse Analysis. London: Routledge.

Halliday, M. A. K. (1978). Language and Social Semiotics. London: Edward Arnold.

He, A. W. (2003). Discourse Analysis. In Aronoff, M. and Rees-Miller, J. (eds.) The Handbook of Linguistics. Oxford: Blackwell Publishing Co.

Hoey, M. (1996). A Clause-relational analysis of selected dictionary entries: Contrast and compatibility in the definitions of 'man' and 'woman'. In Caldas-Coulthard, C. R. and Coulthard, M. (eds.) Texts and Practices: Readings in Critical Discourse Analysis, London: Routledge.

Hoey, M. (2001). Signaling in Discourse: A functional analysis of a common discourse pattern in written and spoken English. In Coulthard, R. M. (ed.) Advances in Written Text Analysis. London: Routledge.

McCarthy, M. (1991). Discourse Analysis for Language Teachers. Cambridge: CUP.

Richards, J. C., Platt, J. and Platt, H. (1993). Longman Dictionary of Language Teaching and Applied Linguistics. England: Longman Group UK Limited.

Sampson, G. (1980). School of Linguistics: Competition and Evaluation. London: Longman.

Tenorio, E. H. (2011). Critical Discourse Analysis: An Overview. The record retrieved from http://ojs.ub.gu.se/ojs/index.php/njes/article/viewFile/658/609 on 02/05/2016.

Van Dijk, T. A. (1995). Aims of Critical Discourse Analysis. Japanese Discourse, 1, 17-27.

Van Dijk, T. A. (1996). Discourse, Power and Access. In Caldas-Coulthard, C. R. and Coulthard, M. (eds.) Texts and Practices: Readings in Critical Discourse Analysis, London: Routledge.

Wallace, C. (1992). Critical literacy awareness in the EFL classroom. In Fairclough, N. (ed.) Critical Language Awareness. London: Longman.

Winter, E. (2001). Clause relations as information structure: Two basic text structures in English. In Coulthard, R. M. (ed.) Advances in Written Text Analysis. London: Routledge.

Wodak, R. (2007). What is Critical Discourse Analysis? Forum: Qualitative Social Research, $8(2)$. 


\title{
Appendix A. The Text
}

'The Dainy Telegraph', Saturdan, Oc tober 14, 2006, No. 47,077, Page 4

\section{Home Office Resists Reform of Drug Law as Coc aine Use Doubles}

\author{
By Philip Johuston: Home Office Editor
}

(1) COCAINE use is on the rise among the urban middle classes, the latest official figures show. (2) Trends uncovered by the British Crime Survey indicate the numbers using the drug since 1998 have doubled. (3) Among young people, use of cocaine has shot up since Labour took office, from 1.4 per cent of 16-to 24-year olds reporting that they used the drug in the past 12 months to nearly six per cent. (4) At the same time, however, overall drug use - including that of cannabis - appears to have declined or remained stable. (5) It is estimated that some two million people used illegal drugs in the past month and 11 million have indulged at some stage in their life time. (6) The Government, which is eight years into a 10-year drug strategy, claimed yesterday that the figures showed it was working. (7) But figures also show little progress on Class A substances, such as cocaine. (8) The Home Office has decided not to reform the drugs classification system, or to introduce new thresholds for possession of illicit substances. (9) Officials have consulted over the past year on options ranging from the most liberal; where up to 500 joints could be considered for 'personal use " to a significant tightening where only 10 'spliffs' were allowed. (10) The government has rejected criticism of the classification system, introduced in 1971, from a Commons committee earlier this year. (11) Vernon Coaker, the Home Office minister, said: 'It is important that there is a coherent system in place to categorise drugs and determine the penalties for their manufactures, possession and supply. (12) I believe that the existing classification system does this effectively, allowing for clear and meaningful distinctions to be made between drugs.' (13) However, Martin Barnes, the chief executive of the charity Drug-Scope, said: 'We are extremely disappointed that the government has reversed the previous Home Secretary's decision to review the system of drug classification, although the door seems to have been left open to return to the issue in the future. (14) The current system was introduced 35 years ago and during that time we have seen a significant increase in levels of drug use and drug-related harms." (15) The Home Office also confirmed plans yesterday to reclassify the drug methylamphetamine, more commonly known as crystal meth, from a Class B to a Class A substance, attracting heavier penalties for possession and trafficking. (16) It was also reported yesterday that at least half of the more expensive residential drug treatment providers in England are under financial pressure because of a lack of referrals. (17) According to the $\mathrm{BBC}$ some centres have been closed, others are under review and beds are not fully occupied.

\section{Copyrights}

Copyright for this article is retained by the author(s), with first publication rights granted to the Journal. This is an open-access article distributed under the terms and conditions of the Creative Commons Attribution license (CC BY-NC-ND) (http://creativecommons.org/licenses/by-nc-nd/4.0/). 